\title{
Relationship between Job Involvement and Job Burnout of Primary and Secondary School Teachers
}

\author{
Hongxiu Tan
}

Shaoguan University, Education School, Guangdong Shaoguan, 512005 China

Keywords: primary and secondary school teachers; job involvement; job burnout

\begin{abstract}
Primary and secondary school teachers are an important guarantee for the cultivation of the next generation of reserve forces in the motherland. Their teaching level and enthusiasm for work are also an important reference index to determine the overall educational strength of our country. Therefore, the study and investigation of the relationship between job involvement and job burnout for primary and secondary school teachers is to carry out our primary and secondary education plan and complete the education body. The reform of the system is of great significance. Through understanding the important role of primary and secondary school teachers' work input, this paper analyzes the reasons for the enthusiasm of their work from several aspects, and finds out the favorable factors for the work of primary and secondary school teachers, so as to help them reduce the level of job burnout in the practical work and help them devote more enthusiasm to the education work.
\end{abstract}

\section{Introduction}

The study of the relationship between job input and job burnout of primary and secondary school teachers is part of the study of psychology. The work complaints and burnout of primary and secondary school teachers mainly reflect their psychological activities. The teachers' physiological, cognitive and emotional effects are put in different degrees through the multiple effects of subjective initiative and objective factors. Get into work and achieve the integration of self and teacher's role. The research shows that the work input of primary and secondary school teachers is related to professional happiness, while professional happiness is embodied in three aspects: personal basic conditions, work environment and self cognition and attitude to work. In practical work, primary and secondary school teachers face a group of children who are not familiar with the world. It is unavoidable to produce job burnout. This means that teachers can not cope with a stressful reaction. The pressure caused by bad emotions and behavior not only seriously affects the physical and mental health of the teachers, but also leads to the decline of the quality of teaching. It affects the students' normal learning. Therefore, this article hopes to explore the causes and solutions of teachers' work and job burnout from the perspective of psychology, hoping to prevent the job burnout of teachers.

\section{The Important Role of Primary and Secondary School Teachers' Job Involvement}

To improve the enthusiasm of primary and secondary school teachers and to reduce their job burnout has a vital role in promoting the education of students and the development of school, so the study and analysis of the relationship between their job input and job burnout can not only integrate the teachers' resources, so that the schools can fully understand the psychology and life of the teachers at the present stage. Status. As the input of the teacher's work is mainly determined by the three aspects of the personal basic conditions, the working environment and the self cognition of the work, the school can fully grasp the dynamic information of all aspects of the teacher in the analysis of these indicators, from the teacher's gender, teaching age, title, calendar, and whether it is married. Schools can know the vitality and concentration of their activities as well as their suggestions and opinions on the school. Therefore, this study not only improves the teaching quality of the teachers, improves the students' efficiency, but also can understand the development of the 
school from the side, so that the school management will make the next development plan and teaching task. The primary and secondary schools should devote themselves to the cultivation of high quality teachers, from the level of teaching to their personal and psychological qualities. Only the teachers themselves feel the high sense of achievement so that they can show the enthusiasm of high vitality, high dedication and high concentration of work, and reduce the negative emotions and job burnout of their own. The primary and secondary schools and the education departments should pay attention to and strengthen the mental health maintenance of teachers, recognize the reasons that affect their work input through a variety of means, and effectively reduce the level of their job burnout, and help teachers to better carry out their educational work[1].

\section{Factors Affecting Primary and Secondary School Teachers' Job Involvement and Job Burnout}

With the passage of teaching career time, the teaching enthusiasm and emotion of primary and secondary school teachers will collapse, and many inhuman factors will be produced, which will increase the degree of teachers' burnout. Schools should analyze various causes of teachers' burnout and cultivate teachers' sense of self fulfillment in order to eliminate their negative emotions.

\subsection{The basic conditions of teachers}

Through a scientific and effective questionnaire survey, it has been proved that primary and secondary school teachers are the most likely stage of job burnout in the three stages of primary and secondary schools, high schools and even universities. Teachers in primary and middle schools are not as good as high school and university teachers in teaching vitality, dedication and concentration. This is because the children of primary and secondary schools have not formed a mature personality, often do some events which are difficult for teachers to deal with, and have influenced the enthusiasm of the teachers for a long time. Primary and secondary school teachers pay much attention to the pressure of teaching in the school, but in the face of mischievous and disobedient students, there will be a lot of trouble that can not be dealt with[2].

In addition, the fact shows that the male teacher's teaching vigor and enthusiasm are obviously higher than that of the female teachers, because the congenital gender advantage and character advantage make the male teachers adjust their mentality quickly when facing the pressure and trouble, and put them into the daily work. For example, in the face of the trouble and error caused by the students, the male teacher can handle the personal life objectively and rationally, but the female teacher may worry too much about the physical and mental condition of the student and lead to the influence of his life.

At the same time, the young teachers whose teaching age is less than five years are obviously superior to the teachers who have more than five years of teaching age in their dedication and work concentration; the degree of work input for master degree teachers is significantly higher than that of the undergraduate degree teachers; the work input of unmarried teachers is significantly higher than that of the married teachers. These studies on the basic conditions of teachers have shown that the basic conditions of the teachers and the length of the entry time are also important factors that affect their work. Teachers with less age, higher education and unmarried teachers are more enthusiastic and active in their work, and have a definite goal for their own career planning, and they are charged with the work of the future. Full of confidence, more willing to show themselves in the teaching work, the release of all of their own power, this sense of confidence and achievement has created a sense of responsibility and mission in their work. Therefore, these indicators are important reference factors for measuring the work engagement of primary and secondary school teachers. It is worth noting that the level of the intermediate title teachers' work input is lower than the primary and senior teachers. The most serious reason for the job burnout of the intermediate title teachers is the pressure of their professional title promotion, which is not only to face the pressure of the title evaluation, but also to repeat the daily teaching tasks, thus reducing the thirst of career development. Summing up power. In contrast, the junior professional title teachers are very enthusiastic about their work, are filled with curiosity and curiosity about their 
work, and are eager to get the approval of the students and colleagues, and there is no desire to increase their salary and increase, so they have more time and energy to work. It is stable and does not require a promotion, so its satisfaction and sense of achievement enable it to focus on work[3].

To sum up, the personal conditions of teachers include the educational stage, sex, teaching age, educational background, marital status and professional title. Each of them has the value of studying the job involvement and job burnout of the teachers. Only through the thorough study of these problems can the teachers help the teachers get out of the haze and devote themselves to their wholehearted investment. Enter the work.

\subsection{Working environment}

The number of male teachers in primary and secondary school teachers in our country is less than that of the teachers. In the course of the teachers, only the teachers are suitable for the male teachers. This situation makes the male teachers generally higher than the female teachers in the level of work input, and the degree and vitality of their work are also significantly higher than those of the female teachers. This is due to the importance of the school to the male teachers. Teacher training and promotion, because of the scarcity of personnel, the school will double to cherish the professional male talent, the school practice in line with the social expectation and use of the male role. This has led to the fact that if primary school female teachers want to achieve the same results and achievements as male teachers, they must invest more time and energy and make more efforts. For a long time, female teachers will have an unfair sense of burnout and lose the power of their original efforts. It has been proved that in the working environment of primary and secondary schools, male teachers are more likely to get the promotion of self value, thus creating a sense of achievement, which helps to regulate their own emotions, alleviate the feeling of burnout in the work, and be more conducive to their work.

From the above facts, it can be seen that the subtle influence of primary and secondary schools can affect the enthusiasm of the teacher's work. The school policy and related teaching plan not only have a profound influence on the students, but also affect the job input and job burnout of the teachers. The most direct influence of the school working environment on Teachers' sense of self value and efficacy is the key factor for teachers to produce the corresponding work motivation. Both active work and slack work are affected by the working environment provided by the school, so a good competitive and welfare working environment can improve teaching. Teachers' efforts, enthusiasm and perseverance in overcoming difficulties[4].

\subsection{The degree of self-cognition}

Through the investigation and analysis of the questionnaire on the job involvement and job burnout of primary and secondary school teachers, it is proved that the teachers' emotional exhaustion and human nature are the important factors that lead to their job burnout, so the teachers' self cognition and self-regulation ability are the important indexes of their work input.

It has been proved that the degree of self-awareness of teachers and the degree of identity of the school's teaching ideas and work programs can help to provide their job input and reduce the corresponding job burnout. The correct and rational cognition can make the related factors of work input positively related, and the factors of personal achievement and work input. The same is also positive.

At the same time, the ability of self-suggestion and adjustment can help teachers improve their sense of identity to teachers' work, and reduce the possibility of burnout, and cultivate a sense of personal achievement for the profession. From a psychological point of view, emotion is the decisive factor in determining a person's work and life, and a positive and positive attitude has a significant positive predictive effect on the work input. With the gradual increase of work intensity and pressure, the emotional exhaustion has a significant negative predictive effect on work input. A good teacher with a good quality must have a good self cognition, stress relief release negative emotions, find the balance between work and life in the pressure of busy work, teaching task and promotion examination, so as to improve the sense of teaching efficiency, enhance the sense of self-improvement, and improve the bad mood. Job burnout increases job involvement enthusiasm. 


\section{Ways to Improve the Enthusiasm of Teachers in Primary and Secondary Schools}

\subsection{Strict screening of teachers' basic conditions}

There are many ways to improve the enthusiasm of teachers in primary and secondary schools. Among them, the basic quality and ability to strictly select teachers should be strictly controlled in school. Because the basic conditions of the individual will have a deep influence on the job input and job burnout in the future, the school should carefully look up the teachers in the recruitment. Gender, age, education and marital status[5].

First of all, the school should strictly control the proportion of male and female teachers, strive for a fair and balanced selection of teachers, put male teachers in the appropriate post of teachers, so that the male teachers are not so "scarce". At the same time, while introducing young teachers, we should also recruit some teachers with working experience, but the teaching age should not be too long. Through the teachers of long teaching age, the new teachers should be promoted. Through the two complementary, they can not only improve the enthusiasm of the work, but also can talk to each other when the work pressure is big, and reduce the work. Irritability. In terms of educational background, schools should mainly introduce highly educated talents. Teachers with higher education level can understand the teaching tasks of the school and think objectively and rationally to think about the problems encountered in the work, and help the school to carry out a series of reforms and innovations.

\subsection{Improve the school management mode and improve the salaries and treatment of teachers.}

The improper management of the school will affect the working state of the teachers, thus making the job burnout. The school should fundamentally improve the management system and improve the psychological activity and teaching mood of the teachers. Schools should take appropriate measures to diversify and equitable management patterns, establish a scientific and rational system of teacher management, and pay attention to the psychological guidance of teachers. The school should eliminate the promotion defects of "male superiority and female inferiority", and optimize the management of teachers by objective evaluation mechanism and reward and punishment system, so that both male and female teachers in middle schools can obtain their own sense of professional identity and professional accomplishment. Schools can create school culture by raising salary treatment and carrying out teachers' internal activities, improve teachers' sense of belonging, and enable teachers to identify the school management policies and teaching objectives, so as to improve the work input of primary and secondary school teachers and alleviate the job burnout of teachers from the school system.

\subsection{Improve teachers' awareness of self-psychological health.}

The consciousness of teachers' self mental health is an important factor in determining their working status and efficiency. The mental health of teachers is not only dominated by students, colleagues and leaders in their work, but also affects mental health through the trivia that occur in daily life. Scientific research shows that there is a certain relationship between the degree of information acquisition and the degree of mental health. Therefore, teachers should know more about the related literature of work input and job burnout, understand their theoretical content and the method of specific evasion, thus timely self test and adjustment, and effectively improve their work efficiency[6].

Teachers' self-confidence and self-knowledge are the basic guarantee for their mental adjustment and enthusiasm for work. The input of teachers with low emotional exhaustion and high sense of achievement is significantly higher than that of other teachers. Primary and secondary school teachers should play their own strengths through daily work, set up a confident image among students and colleagues, control their negative emotions and behaviors in a reasonable range, so as to improve the positive impact of self-efficacy. In the same way, the sense of teaching efficacy also regulates job burnout. In the face of pressure and frustration, teachers with low teaching efficacy will have a suspicion of their own teaching ability, thus intensifying their negative emotions and prone to job burnout. Only teachers with high mental health can find happiness in their work, 
devote themselves to work and get more professional happiness.

\section{Conclusion}

There are many factors closely related to the job involvement and job burnout of primary and secondary school teachers. Modern educators must fully understand the importance of primary and secondary school teachers' work input so as to find ways to improve the enthusiasm of primary and secondary school teachers and eliminate job burnout in practice and provide the educational undertakings of our country. Good help.

\section{Acknowledgment}

Fund Project :2017 Special innovation projects in Colleges and Universities of Guangdong Provincial Education Department”Influencing factors and intervention strategies of primary and secondary school teachers' job engagement in northern Guangdong”([2018]64 document of Guangdong Science and technology department),2017 Teaching quality and teaching reform project in Guangdong Universities”Psychology major practice teaching base of school, government and enterprise of Shaoguan University”([2017]214 document of Guangdong high education),2017 Shaoguan special research project on the development of primary and secondary school teachers "Study on the current situation and influencing factors and intervention strategies of primary and secondary school teachers' burnout in Shaoguan”,2015 teaching quality and teaching reform project in Guangdong province's undergraduate colleges and universities"teaching team of teachers education class”([2015]133 document of Guangdong high education )

\section{References}

[1] Motallebi K, Kiani Q. The Correlation between Job Burnout and Mental Health of Teachers in Special Schools of Zanjan: Mediation of Job Involvement [J]. 2017, 7(1):52-60.

[2] Nwankwo B E, Agu S A, Sydneyabor N, et al. The Relationship between Job Satisfaction and Job Involvement among Secondary School Teachers [J]. Social Science Electronic Publishing, 2016.

[3] Bermejotoro L, Prietoursúa M, Hernández V. Towards a model of teacher well-being: personal and job resources involved in teacher burnout and engagement [J]. Educational Psychology, 2016, 36(3):1-21.

[4] Jenaabadi H, Nejad B A, Abadi F S M, et al. Relationship of Workaholism with Stress and Job Burnout of Elementary School Teachers[J]. Health, 2016, 8(1):1-8.

[5] Zhang H X, Zhang H, Sun W G, et al. Analysis on influencing factors of job burnout among teachers in primary and secondary schools of Yan'an City[J]. Occupation \& Health, 2016.

[6] Olusa A O. Influence of Job Demand and Job Status on Job Involvement among Non-Burnout Employees [J]. Ife Psychologia An International Journal, 2016, 23(2):145-155. 